\title{
Monocular acquisition and interocular transfer in albino rats with unilateral striate ablations'
}

\author{
DONMELL J. CREEL ${ }^{2}$ AND CHARLES L. SHERIDAN \\ THE UNIVERSITY OF MISSOURI AND VETERANS ADMINISTRATION HOSPITAL, KANSAS CITY, MISSOURI
}

\begin{abstract}
Monocular acquisition and interocular transfer of a horizontal-vertical discrimination were measured in 18 albino rats with unilateral lesions of the striate cortex and in 9 unoperated Ss. Ss trained with the eye contralateral to the lesion failed to learn the discrimination unless it had previously been acquired via the ipsilateral eye. Ss trained via the ipsilateral eye learned quickly if ipsilateral-eye training came first, but performed erratically if ipsilateral training followed contralateral training. Interocular transfer occurred in unoperated Ss, but it was incomplete.
\end{abstract}

In the past, brain lesion studies have centered almost exclusively on the effects of bilaterally placed lesions. This is because the functional equivalence of the cerebral hemispheres tends to obscure any effects of unilateral damage. In the albino rat visual system, however, hemispheric equivalence can be minimized by the simple expedient of restricting visual input to a single eye. Nearly all of the albino rat's optic fibers project to the contralateral hemisphere (Lund, 1965; Sheridan \& Shrout, 1966) and communication between the hemispheres is minimal (Sheridan, 1965; Sheridan \& Shrout, 1965). In the experiment reported here, advantage is taken of this characteristic of the albino rat in order to measure the effects of unilateral ablation of the "visual" cortex.

Subjects

Ss were 27 experimentally naive male albino rats of the Sprague-Dawley strain.

\section{Apparatus}

The apparatus, a Thompson-Bryant box (Thompson \& Bryant, 1955), utilized escape from shock as reinforcement, and consisted of a start box, runway, choice point with two alternative entryways, and a goalbox. Procedure

In 18 randomly selected Ss, the visual cortex was aspirated unilaterally, on the right side in nine cases and on the left side in the remaining nine. First-eye training with the eye ipsilateral to the lesion was given to five left- and four right-lesioned Ss, and first-eye training with the eye contralateral to the lesion was given to four left- and five right-lesioned Ss. Five unoperated Ss were trained with the right eye first and four with the left eye first.

After the operated animals had been allowed a minimum of 3 weeks recovery time, Ss were pretrained to run to the goalbox, and to knock over grey stimulus cards which blocked the goalbox entryways. One eye was then covered with a black vinyl acrylic contact occluder (Schuck \& Copolla, 1963), which covered the eye to its base, and Ss were trained to discriminate horizontal from vertical $1 / 2 \mathrm{in}$. stripes.

There were 25 trials each day after pretraining. Side of the correct stimulus was varied across trials according to a Gellermann series (Gellermann, 1933).

All Ss were run to a criterion of 18 correct out of any block of 20 trials, or until 300 trials had been run without meeting the $18 / 20$ criterion. The occluder was removed from those Ss reaching criterion and was immediately reapplied to the same eye; overtraining proceded until $S$ again met the $18 / 20$ criterion.

After overtraining or the completion of 300 trials, the occluders were switched to the opposite eye, then all Ss underwent discrimination training using only the previously occluded eye. Ss that originally failed to learn the pattern discrimination within 300 trials were given a minimum of 75 trials with the opposite eye occluded. If Ss did not show any indication of learning the discrimination within the prescribed number of trials, training was terminated. Immediately following training, both eyes were occluded and Ss were run a minimum of 10 trials to evaluate the effectiveness of the occluders.

At the end of the experiment, all operated Ss were perfused with saline, then $10 \%$ formalin. The brains were removed and examined for gross external damage. They were embedded in paraffin and cut with every tenth 30 micron section taken for the extent of the lesion, and with every section for the extent of the lateral geniculate bodies. The lateral geniculates of both hemispheres were examined microscopically for degeneration.

Results

Binocular occlusion test. With both eyes occluded, all Ss performed at chance levels except one in the contralateral group. This $S$ showed no impairment of discrimination with both eyes covered. His data are not reported here.

Anatomical findings. Examination of cortex and lateral geniculate bodies indicated that all lesions were complete.

Acquisition, overtraining and transfer. Table 1 summarizes measures of original acquisition, overtraining, and interocular transfer. None of the Ss in the contralateral group reached criterion within the stipulated 300 trials. In original or first-eye acquisition the ipsilateral group and normal controls reached criterion in 60.5 and 75.6 mean trials, respectively. The 15.1 difference in mean trials to criterion for ipsilateral Ss vs. unoperated controls is just short of the .05 level 
Table 1. Trials to criterion for original acquisition, overtraining, and interocular transfer.

\begin{tabular}{|c|c|c|c|c|}
\hline Lesion & Occlusion & Acquisition & Overtraining & Transfer \\
\hline \multicolumn{5}{|c|}{ Unoperated Ss } \\
\hline None & Left & 97 & 21 & 30 \\
\hline None & L & 67 & 0 & 0 \\
\hline None & L & 92 & 0 & 11 \\
\hline None & L & 82 & 27 & 10 \\
\hline None & $\mathrm{L}$ & 82 & 0 & 8 \\
\hline None & Right & 58 & 0 & 24 \\
\hline None & $\mathrm{R}$ & 100 & 0 & 5 \\
\hline None & $\mathbf{R}$ & 58 & 0 & 66 \\
\hline None & $\mathbf{R}$ & 45 & 15 & 19 \\
\hline \multicolumn{5}{|c|}{ Ipsilateral Ss } \\
\hline Right & Left & 48 & 7 & 162 \\
\hline$R$ & $\mathrm{~L}$ & 61 & 0 & 175 \\
\hline $\mathrm{R}$ & $\mathrm{L}$ & 77 & 0 & 12 \\
\hline R & $L$ & 63 & 16 & 20 \\
\hline $\mathrm{R}$ & $\mathrm{L}$ & 80 & 31 & * \\
\hline Left & Right & 58 & 0 & 34 \\
\hline L & $\mathrm{R}$ & 30 & 20 & $\begin{array}{l}34 \\
91\end{array}$ \\
\hline L & $R$ & 51 & 17 & 69 \\
\hline $\mathrm{L}$ & $\mathrm{R}$ & 77 & 0 & 65 \\
\hline \multicolumn{5}{|c|}{ Contralateral Ss } \\
\hline Left & Left & $*$ & $*$ & 31 \\
\hline L & L & $*$ & * & * \\
\hline $\mathrm{L}$ & $L$ & * & $*$ & * \\
\hline $\mathrm{L}$ & $\bar{L}$ & * & $*$ & * \\
\hline Right & Right & * & * & 10 \\
\hline$R$ & $\mathrm{R}$ & * & * & 11 \\
\hline R & $\mathrm{R}$ & * & * & * \\
\hline
\end{tabular}

* $S$ did not meet criterion within the stipulated number of trials (300 for acquisition, 75-300 for transfer)

$(\mathrm{F}=3.68, \mathrm{df}=1 / 16, \mathrm{p}<.07)$. Ipsilateral and unoperated Ss did not differ appreciably in the number of trials necessary to reach the overtraining criterion of $18 / 20$ with the original eye. None of the contralateral group reached the overtraining stage of the experiment.

During second-eye acquisition, ipsilateral Ss (now using the eye contralateral to the lesion) met criterion in 75 mean trials. The contralateral group, when shifted to the second (ipsilateral) eye, performed erratically. Many of them perseverated in position responding which had developed during first-eye training.

Inspection of the individual first- and second-eye trials to criterion reveals that unoperated Ss showed considerable interocular transfer. However, comparison of trials taken to meet criterion a second time on the originally trained eye (overtraining criterion) with trials to criterion on the second eye indicated that transfer was less than complete ( $p<.02$, Sign test).

\section{Discussion}

It is probable that a single structural variable-the number of optic fibers mediating discrimination-is responsible for the marked differences between ipsilateral and contralateral Ss. If pattern discrimination is cortically dependent and if nearly all of the optic fibers decussate in albino rats (Lund, 1965), ipsilateral Ss use an optic input only slightly less elaborate than normal, whereas contralateral Ss must rely on the sparse uncrossed optic fiber input. This interpretation is not inconsistent with the finding that Ss first trained while utilizing crossed fibers were able to reach criterion when shifted to the opposite eye, whereas Ss trained initially via uncrossed fibers did not reach criterional levels. Presumably, this means that the uncrossed pathways can mediate recognition and retention but not acquisition of the discrimination.

Interocular transfer was incomplete in unoperated Ss, but emphasis should be placed on the large amount of savings during second-eye acquisition. Previous reports have indicated very low level interocular transfer in albino rats (Sheridan, 1965; Sheridan \& Shrout, 1965 ), but $45^{\circ}$ vs. $135^{\circ}$ stripes were used as discriminanda.

\section{References}

Gellerman, L. W. Chance orders of alternating stimuli in visual discrimination experiments. J. genet. Psychol., 1933, 42, 206208.

Lund, R. D. Uncrossed visual pathways of hooded and albino rats. Science, 1965, 149, 1506-1507.

Shuck, J. R., \& Copolla, L. A. Contact occluders for restricting vision in the rat. Amer. J. Psychol., 1963, 76, 135-137.

Sheridan, C. L. Interocular transfer of brightness and pattem discriminations in normal and corpus callosum-sectioned rats. $J$. comp. physiol. Psychol., 1965, 59, 229-294.

Sheridan, C. L., \& Shrout, L. L. Interocular transfer in the rat: the the role of the occlusion process. Psychon. Sci.,1965, 2,173-174.

Sheridan, C. L., \& Shrout, L. L. Differences in the effectiveness of optic uncrossed fiber systems in albino and hooded rats. Psychon. Sci., 1966, 4, 177-178.

Thompson, R., \& Bryant, H. Memory as affected by activity of the relevant receptor. Psychol. Rep., 1955, 1, 393-400.

\section{Notes}

1. Supported by Veterans Administration 8200 (Research) funds. Manuscript preparation was facilitated by Grant MH-12268-01 from the U. S. Public Health Service to Charles Sheridan. This report is based on an M. A. thesis submitted by the senior author to the Department of Psychology, University of Missouri at Kansas City. 2. Now at the University of Utah and V. A. Hospital, Salt Lake City. 